\title{
Clinical pathological characteristics of breast cancer patients with secondary diabetes after systemic therapy: a retrospective multicenter study
}

\author{
Li Juanjuan ${ }^{1}$ - Wei Wen ${ }^{1}$ - Liu Zhongfen ${ }^{1}$. Chen Chuang ${ }^{1}$ - Cheng Jing ${ }^{2}$. \\ Gong Yiping $^{3} \cdot$ Wang Changhua ${ }^{4} \cdot$ Yu Dehua $^{1} \cdot$ Sun Shengrong ${ }^{1}$
}

Received: 16 September 2014 / Accepted: 24 March 2015 / Published online: 9 April 2015

(C) The Author(s) 2015. This article is published with open access at Springerlink.com

\begin{abstract}
The objective of this study was to investigate the clinical pathological characteristics of breast cancer (BC) patients with secondary diabetes after systemic therapy without preexisting diabetes. A total of $1434 \mathrm{BC}$ patients received systemic therapy and were analyzed retrospectively. Fasting plasma glucose (FPG) levels were monitored prior to the treatments, during the course of systemic therapy, and at the follow-up visits. Cox regression models were used to estimate the associations between the clinical pathological characteristics of BC and the cause-specific hazard of developing secondary diabetes. Among the $1434 \mathrm{BC}$ patients, 151 had preexisting type 2 diabetes. Of the remaining 1283 patients with normal FPG levels prior to the systemic therapy, 59 developed secondary diabetes and 72 displayed secondary impaired fasting glucose (IFG) over a mean follow-up of 41 months. The prevalence of secondary type 2 diabetes in BC patients was $4.6 \%(59 / 1283)$, which was obviously higher than that of the normal control group $(1.4 \%, P<0.001)$. The percentage of older patients $(P<0.05)$, menopausal patients $(P<0.001)$, and obese patients $(P<0.01)$ tended to be lower in the secondary diabetic group. In addition, these patients
\end{abstract}

Li Juanjuan and Wei Wen contributed equally to this work.

Sun Shengrong

sun137@sina.com

1 Department of Breast and Thyroid Surgery, Wuhan University, Renmin Hospital, Wuhan 430060, China

2 Cancer Center, Union Hospital, Tongji Medical College, Huazhong University of Science and Technology, Wuhan 430022, China

3 Department of Breast Surgery, Hubei Cancer University, Wuhan 430079, China

4 Department of Pathology and Pathophysiology, Wuhan University School of Basic Medical Sciences, Wuhan 430071, China with secondary diabetes had later pathological stages $(P<0.01)$, more lymph node metastasis $(P<0.05)$, negative estrogen receptor (ER) expression $(P<0.05)$, and smaller size of tumors $(P<0.05)$. After adjusting for age and BMI, the risk of developing secondary diabetes and IFG in subjects with later pathological stage $\mathrm{BC}$ (hazard ratio $(\mathrm{HR})=1.623 ; 95 \%$ confidence interval $(\mathrm{CI}) 1.128-2.335(P<0.01)$ ), negative progesterone receptor $(\mathrm{PR})$ expression $(\mathrm{HR}=0.530 ; 95 \% \mathrm{CI}$ $0.372-0.755(P<0.001))$, positive human epidermal growth factor receptor 2 (HER2) expression $(\mathrm{HR}=1.822 ; 95 \% \mathrm{CI}$ $1.230-2.700(P<0.01))$, and more lymph node metastasis $(\mathrm{HR}=1.595 ; 95 \%$ CI $1.128-2.258(P<0.01))$ was significantly higher. In conclusion, this study shows that an increase in the incidence of diabetes among breast cancer survivors after systemic therapy, especially the patients with later pathological stages, more lymph node metastasis, negative hormone receptor expression, and positive HER2 expression. Our study suggests that greater diabetes screening and prevention strategies among breast cancer patients after systemic treatment are needed in China.

Keywords Breast cancer $\cdot$ Type 2 diabetes $\cdot$ Systemic therapy $\cdot$ Clinical features $\cdot$ Pathological features

\section{Introduction}

Breast cancer $(\mathrm{BC})$ and diabetes mellitus are common diseases and major health care problems among females in the world. The overall prevalence of diagnosed diabetes was $11.6 \%$ among the Chinese adults, $12.1 \%$ among men, and $11.0 \%$ among women [1]. Breast cancer accounted for $25.2 \%$ of all cancers and $14.7 \%$ of cancer deaths in females worldwide in 2012 [2]. In China, breast cancer is currently the most 
common malignant tumor, and as a result, it is the second leading cause of cancer deaths in women [3].

Many BC patients are also diagnosed with preexisting diabetes, possibly due to the shared etiology and signaling pathways $[4,5]$. These include old age; obesity; genetic predisposition; a sedentary lifestyle; metabolic syndrome; as well as biological factors such as hyperinsulinemia, hyperglycemia, and chronic inflammation [6-10]. Epidemiological studies suggest that type 2 diabetes mellitus (T2DM) increases breast cancer risk and thereafter goes with an increased mortality. A study by Larsson et al. suggested that females with diabetes had a $20 \%$ increased risk of postmenopausal breast cancer. Interestingly, the statistical association between diabetes and breast cancer is significantly stronger in Asia than that in North America [4]. Diabetes may influence therapy choices, affect therapeutic toxicities, and cause worse outcomes. Further studies suggested that diabetes was associated with a 40$50 \%$ increased mortality in $\mathrm{BC}$ patients [7, 8]. In addition, the risk of developing $\mathrm{BC}$ increased significantly after the longterm use of insulin glargine [11].

On the other hand, emerging evidence suggests that females with $\mathrm{BC}$ have an increased risk of developing diabetes. Lipscombe et al. reported that $9.7 \%$ of older females with early-stage $\mathrm{BC}$ developed diabetes after adjuvant therapy for a median follow-up of 5.8 years. The risk started to increase 2 years after diagnosis, especially for the patients who received adjuvant chemotherapy [12]. A recent populationbased retrospective study found that previously undiagnosed diabetes was associated with advanced-stage cancer and increased mortality [13]. However, no study has been reported that whether secondary diabetes is associated with chemotherapy in both young and older females with breast cancer and how it is affected by clinical pathological characteristics.

In this study, we focused on the clinical pathological characteristics of breast cancer patients with secondary diabetes after systemic therapy without preexisting diabetes and tried to provide the clinical guidance for these patients.

\section{Subjects and methods}

\section{Subjects}

With Ethics Committee approval, we retrospectively evaluated 1434 patients with BC aged 20-80 years who were treated in Renmin Hospital of Wuhan University, Hubei Cancer Hospital, and Union Hospital of Tongji Medical College, Wuhan, China, between January 2008 and July 2014. All the patients were diagnosed by pathological examination. The diagnosis of type 2 diabetes mellitus was based on the following criteria: the medical history and prescription records which were obtained by doctors during interview and the definition of the 1999 World Health Organization (WHO), including a fasting plasma glucose $(\mathrm{FPG}) \geq 7.0 \mathrm{mmol} / \mathrm{L}$, a random plasma glucose $\geq 11.1 \mathrm{mmol} / \mathrm{L}$, or a 2 -h plasma glucose $\geq 11.1 \mathrm{mmol} / \mathrm{L}$ during an oral glucose tolerance test (OGTT). Impaired fasting glucose (IFG) was defined as values above normal, but below the diagnostic cutoff for diabetes $(\geq 6.1$ to $<7.0 \mathrm{mmol} / \mathrm{L}$ ) [14]. All the patients accepted the following exclusion criteria: (1) type 1 diabetes mellitus, (2) history of cancer, and (3) male patient. Finally, all the patients included in our study had complete data available and received systemic treatment including surgery and chemotherapy.

\section{Data collection}

Both demographic information and medical records were collected for analysis. The demographic information included age at the time of breast cancer diagnosis, height, and weight. The medical history recorded included a previous history of diabetes, menopausal status, age of onset of menarche, family history of breast cancer, stage of breast cancer at the time of diagnosis, hormonal receptor status (estrogen, progesterone) by immunohistochemistry (IHC) assay, human epidermal growth factor receptor 2 (HER2)/neu status by either an IHC assay or a fluorescence in situ hybridization (FISH) assay (HER2-positive means FISH-amplified or IHC3+; HER2negative means FISH-non-amplified or IHC $0-1+$; IHC2+ is defined as borderline which requires FISH assay.), lymph node status, surgical therapy, chemotherapeutic records, laboratory results, recurrence of breast cancer, history of bilateral breast cancer, and survival of the patients since the diagnosis of cancer (in months). Death was validated using social security records. Obesity (BMI $\left.\geq 25 \mathrm{~kg} / \mathrm{m}^{2}\right)$ was diagnosed according to the Asia-Pacific criteria [15]. Detailed information is presented in Table 1.

Previously diagnosed diabetes among the breast cancer patients was determined on the self-report and the medical record. As part of routine clinical care, FPG levels were determined presurgery, before the commencement of each chemotherapy cycle, and at 3-6 months intervals after the final cycle. The management of diabetes (including dietary control, oral drugs, or insulin) and the discontinuation of chemotherapy were recorded. All the patients that were diagnosed with diabetes were referred to an endocrinologist. Cohort entry date was defined as the date of breast cancer diagnosis.

\section{Treatment}

All BC patients received surgical treatment and chemotherapy. In addition, most patients with diabetes were treated with oral hypoglycemic agents or insulin. The systemic treatment for $\mathrm{BC}$ was performed according to guidelines and standard protocols. All BC patients received modified radical or simplified mastectomy. Chemotherapy included anthracyclinebased combined chemotherapy, paclitaxel/docetaxel alone or 
Table 1 General characteristics of patients with diabetes and impaired fasting glucose

\begin{tabular}{|c|c|c|c|c|}
\hline General characteristics & $\begin{array}{l}\text { Preexisting } \\
\text { diabetes } \\
(n=151)\end{array}$ & $\begin{array}{l}\text { Secondary } \\
\text { diabetes } \\
(n=59)\end{array}$ & $\begin{array}{l}\text { Secondary } \\
\text { IFG }(n=72)\end{array}$ & $P$ values \\
\hline Age (years), mean $\pm \mathrm{SD}$ & $54.43 \pm 8.97$ & $54.90 \pm 9.35$ & $51.07 \pm 9.62$ & 0.021 \\
\hline \multicolumn{5}{|l|}{ Urban/rural status } \\
\hline $\begin{array}{l}\text { Urban } \\
\text { Rural }\end{array}$ & $\begin{array}{l}98(64.90 \%) \\
53(35.10 \%)\end{array}$ & $\begin{array}{l}44(74.58 \%) \\
15(25.42 \%)\end{array}$ & $\begin{array}{l}48(66.67 \%) \\
24(33.33 \%)\end{array}$ & 0.401 \\
\hline \multicolumn{5}{|l|}{ Family history of $\mathrm{BC}$ in first degree relatives } \\
\hline $\begin{array}{l}\text { Positive } \\
\text { Negative }\end{array}$ & $\begin{array}{c}7(4.64 \%) \\
144(95.36 \%)\end{array}$ & $\begin{array}{c}1(1.70 \%) \\
58(98.30 \%)\end{array}$ & $\begin{array}{c}1(1.39 \%) \\
71(98.61 \%)\end{array}$ & 0.332 \\
\hline Age of onset of menarche (years), mean $\pm \mathrm{SD}$ & $13.82 \pm 1.45$ & $13.08 \pm 1.32$ & $12.73 \pm 1.33$ & $<0.001$ \\
\hline \multicolumn{5}{|l|}{ Menopause status } \\
\hline $\begin{array}{l}\text { Premenopausal } \\
\text { Postmenopausal }\end{array}$ & $\begin{array}{r}49(32.45 \%) \\
102(67.55 \%)\end{array}$ & $\begin{array}{l}17(28.81 \%) \\
42(71.19 \%)\end{array}$ & $\begin{array}{l}35(48.61 \%) \\
37(51.39 \%)\end{array}$ & $<0.001$ \\
\hline \multicolumn{5}{|l|}{ Age at first live birth (years) } \\
\hline $\begin{array}{l}20-29 \\
\geq 30\end{array}$ & $\begin{array}{c}140(92.72 \%) \\
11(7.28 \%)\end{array}$ & $\begin{array}{r}53(89.83 \%) \\
6(10.17 \%)\end{array}$ & $\begin{array}{c}65(90.28 \%) \\
7(9.72 \%)\end{array}$ & 0.728 \\
\hline \multicolumn{5}{|l|}{ Breastfeeding (months) } \\
\hline $0-6$ & $15(9.93 \%)$ & $6(10.17 \%)$ & $9(12.50 \%)$ & \\
\hline$\geq 7$ & $136(90.07 \%)$ & $53(89.83 \%)$ & $63(87.50 \%)$ & 0.837 \\
\hline BMI $\left(\mathrm{kg} / \mathrm{m}^{2}\right)$, mean $\pm \mathrm{SD}$ & $24.86 \pm 2.44$ & $23.92 \pm 1.59$ & $23.19 \pm 1.31$ & $<0.01$ \\
\hline
\end{tabular}

Data are expressed as means \pm SD or $n(\%)$ combined with other drugs, and second-line chemotherapy regimen (such as capecitabine, gemcitabine, platinums, and vinorelbine). Adverse events (AE) were documented daily during chemotherapy and were classified according to the Common Terminology Criteria for Adverse Events (version 4.0) for final analysis [16]. Radiotherapy, endocrine therapy, and HER2-targeted therapies were given following guidelines and standard protocols.

\section{Outcome and follow-up}

Our primary outcome was a diagnosis of diabetes from cohort entry date until July 2014. Diabetes was identified according to the definition of the 1999 WHO [14]. Persons in the cohort were followed until the incidence of diabetes, the recurrence of breast cancer, the occurrence of a new malignancy, death, or the end of the follow-up period.

\section{Statistical analysis}

Data were stored in an Excel database by three research assistants, and descriptive statistics were calculated for all the study variables. The basic conditions and clinical pathological characteristics of the patients were tested using the $X^{2}$ test. The median onset time of secondary diabetes was analyzed between each group using a Kaplan-Meier analysis, and the significance test was performed using the log-rank test. The Cox proportional hazard model was used to examine the correlation between each clinical pathological characteristics and the occurrence of secondary diabetes. The factors included in the Cox multifactorial regression model were both statistical and clinical factors, including age, menopausal status (postand premenopausal), pathology reports of the lymph nodes (with and without lymph node metastasis), TNM stage (early and advanced stage), expression of estrogen receptor (ER; positive and negative), expression of progesterone receptor (PR; positive and negative), and expression of HER2 (positive, negative, and borderline). Statistical analysis was performed using SPSS (version 17.0). All tests of statistical significance were based on a two-sided $P<0.05$.

\section{Results}

\section{Increased incidence of $\mathrm{BC}$ patients with secondary diabetes following systemic therapy}

The median follow-up time for this study was 41 months (1666 months). A total of 1434 BC patients treated with systematic therapy with available FPG data were included in the study. Of these, $10.5 \%(151 / 1434)$ had preexisting diabetes. The FPG was measured with the remaining 1283 patients without preexisting diabetes during each chemotherapy cycle and at 3-6 months intervals after the final cycle, based on the available data and follow-up results. There were $89.8 \%$ $(1152 / 1283)$ of the patients with normal FPG levels throughout the whole study period. Approximately $10.2 \%(131 / 1283)$ of the patients developed hyperglycemia during systemic 
therapy, including $5.6 \%(72 / 1283)$ with secondary IFG and $4.6 \%(59 / 1283)$ with secondary diabetes. Detailed information describing these three groups is summarized in Fig. 1.

In addition, 1361 females without $\mathrm{BC}$ or preexisting type 2 diabetes who received an annual routine physical examination at Renmin Hospital of Wuhan University were followed up for 3 year as the normal control group. Of these, $3 \%(41 / 1361)$ developed hyperglycemia, including $1.6 \%(22 / 1361)$ with IFG and $1.4 \%(19 / 1361)$ with diabetes. These percentages were significantly lower than those of $\mathrm{BC}$ patients $(P<0.001)$.

\section{Clinical pathological characteristics of $\mathrm{BC}$ patients with secondary diabetes and IFG}

The clinical pathological characteristics of the secondary diabetic group and control groups are summarized in Table 1 . The mean age of patients with preexisting diabetes was $54.43 \pm 8.97$ years, which was older than that of the secondary IFG BC group (51.07 \pm 9.62 years, $P<0.05)$. The mean age of patients with normal FPG during the follow-up was $43.33 \pm$ 3.59 years, which was younger than that of the other groups $(P<0.001)$. Among the $\mathrm{BC}$ patients with preexisting diabetes, the percentage of postmenopausal patients was $67.55 \%$, which was significantly higher than that of the groups with secondary IFG and diabetes $(P<0.001)$, while the percentage of postmenopausal patients was $42.62 \%$ among the $\mathrm{BC}$ patients with normal FPG during the follow-up, which was significantly lower than the other groups $(P<0.001)$. The mean age of onset of menarche in the secondary IFG BC patients was significantly younger than that of the other two groups $(P<0.001)$. BMI of patients with preexisting diabetes was significantly higher than that of the other groups $(P<0.01)$. There were no significant differences in urban/rural habitation, family history of $\mathrm{BC}$ in first degree relatives, and age at first live birth and breastfeeding.

Of the patients who developed secondary diabetes, $52.5 \%$ (31/59) were diagnosed initially with advanced-stage BC (stages III/IV), while $31.1 \%(47 / 151)$ of patients with preexisting diabetes were diagnosed initially with advanced BC. The results show that the percentage of advanced-stage $\mathrm{BC}$ was higher in the secondary diabetes group (Table 2, $P<0.01)$. In the secondary diabetes group, patients tend to have more lymph node metastasis than the other two groups $(P<0.05)$. In addition, patients with preexisting diabetes had larger average tumor sizes than the patients with secondary diabetes and secondary IFG $(P<0.05)$. Meanwhile, in the secondary diabetes group, patients tended to have higher percentages of negative ER expression than the other two groups $(P<0.05)$. There were no significant differences in other indicators among these groups (Table 2).

\section{Risk analysis for $\mathrm{BC}$ patients with secondary diabetes and IFG}

A total of 59 patients developed secondary diabetes during a median follow-up of 41 months. Meanwhile, 72 patients developed secondary IFG, a status of prediabetes, which was also associated with an increased risk of cancer [17]. All factors for each group were included in the Kaplan-Meier analysis, and there were significant differences in clinicopathological features including menopausal status $(P=0.003)$; pathological stages $(P<0.001)$; lymph node status $(P=0.009)$; and

Fig. 1 Patient flow diagram

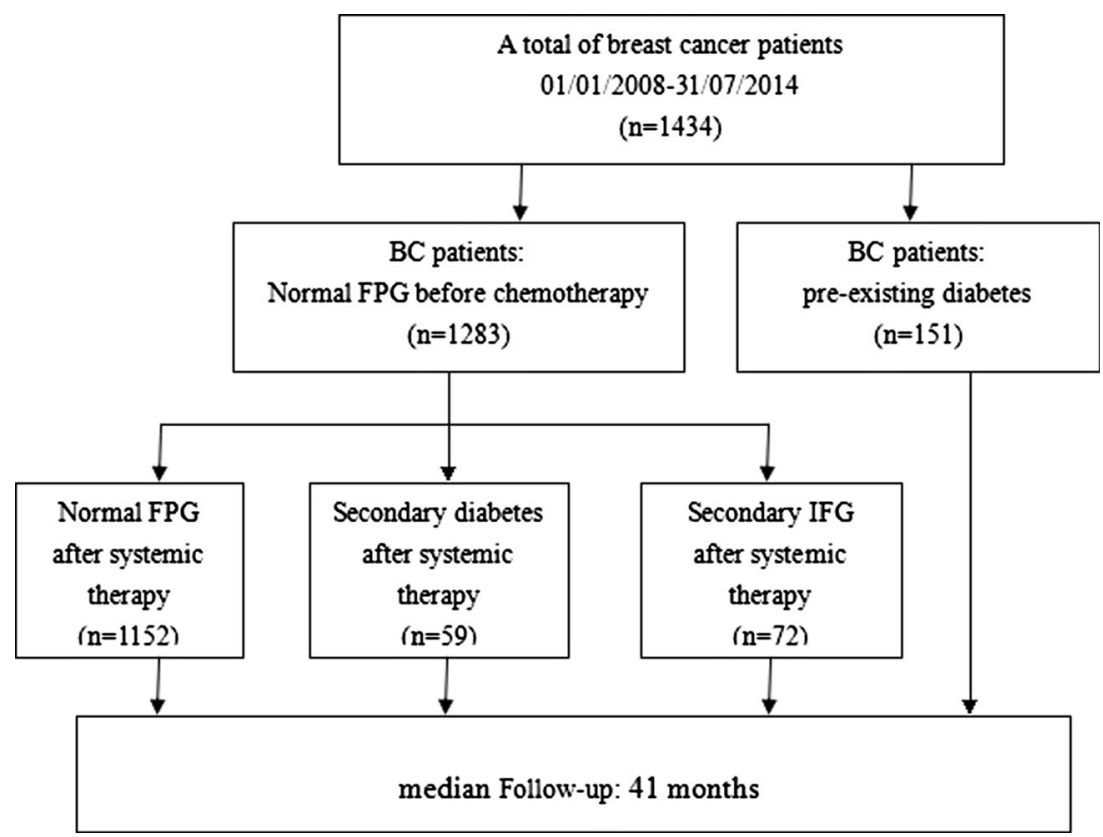


Table 2 Clinical pathological characteristics and follow-up of breast cancer patients with secondary diabetes or impaired fasting glucose (IFG)

\begin{tabular}{|c|c|c|c|c|}
\hline $\begin{array}{l}\text { Pathological } \\
\text { characteristics }\end{array}$ & $\begin{array}{l}\text { Preexisting hyperglycemia } \\
(n=151)\end{array}$ & $\begin{array}{l}\text { Secondary } \\
\text { diabetes }(n=59)\end{array}$ & $\begin{array}{l}\text { Secondary } \\
\operatorname{IFG}(n=72)\end{array}$ & $P$ values \\
\hline Stage & & & & 0.038 \\
\hline I & $35(23.18 \%)$ & $10(16.95 \%)$ & $16(22.22 \%)$ & \\
\hline II & $69(45.70 \%)$ & $18(30.51 \%)$ & $35(48.61 \%)$ & \\
\hline III & $45(29.80 \%)$ & $31(52.54 \%)$ & $19(26.39 \%)$ & \\
\hline IV & $2(1.32 \%)$ & 0 & $2(2.78 \%)$ & \\
\hline Tumor & & & & 0.048 \\
\hline $\mathrm{T}_{1}$ & $39(25.83 \%)$ & $15(25.42 \%)$ & $26(36.11 \%)$ & \\
\hline $\mathrm{T}_{2}$ & $90(59.60 \%)$ & $26(44.07 \%)$ & $38(52.78 \%)$ & \\
\hline $\mathrm{T}_{3}$ & $14(9.27 \%)$ & $17(28.81 \%)$ & $8(11.11 \%)$ & \\
\hline $\mathrm{T}_{4}$ & $8(5.30 \%)$ & $1(1.70 \%)$ & 0 & \\
\hline Lymph node & & & & 0.041 \\
\hline $\mathrm{N}_{0}$ & $75(49.67 \%)$ & $23(38.98 \%)$ & $34(47.22 \%)$ & \\
\hline $\mathrm{N}_{1}$ & $37(24.50 \%)$ & $6(10.17 \%)$ & $20(27.78 \%)$ & \\
\hline $\mathrm{N}_{2}$ & $18(11.92 \%)$ & $13(22.03 \%)$ & $5(6.94 \%)$ & \\
\hline $\mathrm{N}_{3}$ & $21(13.91 \%)$ & $17(28.82 \%)$ & $13(18.06 \%)$ & \\
\hline Metastasis (at diagnosis) & & & & 0.467 \\
\hline $\mathrm{M}_{0}$ & $148(98.01 \%)$ & $59(100 \%)$ & $70(97.22 \%)$ & \\
\hline $\mathrm{M}_{1}$ & $3(1.99 \%)$ & 0 & $2(2.78 \%)$ & \\
\hline Stage (at diagnosis) & & & & 0.007 \\
\hline Early & $104(68.87 \%)$ & $28(47.46 \%)$ & $51(70.83 \%)$ & \\
\hline Advanced & $47(31.13 \%)$ & $31(52.54 \%)$ & $21(29.17 \%)$ & \\
\hline \multicolumn{5}{|l|}{ Hormone receptor } \\
\hline ER positive & $108(71.52 \%)$ & $37(62.71 \%)$ & $38(52.78 \%)$ & 0.022 \\
\hline ER negative & $43(28.48 \%)$ & $22(37.29 \%)$ & $34(47.22 \%)$ & \\
\hline PR positive & $84(55.63 \%)$ & $33(55.93 \%)$ & $32(44.44 \%)$ & 0.255 \\
\hline PR negative & $67(44.37 \%)$ & $26(44.07 \%)$ & $40(55.56 \%)$ & \\
\hline \multicolumn{5}{|l|}{ HER2 } \\
\hline Positive & $41(27.15 \%)$ & $17(28.81 \%)$ & $23(31.94 \%)$ & 0.333 \\
\hline Negative & $96(63.58 \%)$ & $32(54.24 \%)$ & $48(66.67 \%)$ & \\
\hline Borderline & $14(9.27 \%)$ & $10(16.95 \%)$ & $1(1.39 \%)$ & \\
\hline Recurrence & & & & $<0.001$ \\
\hline No & $134(88.74 \%)$ & $48(81.36 \%)$ & $59(81.94 \%)$ & \\
\hline Yes & $17(11.26 \%)$ & $11(18.64 \%)$ & $13(18.06 \%)$ & \\
\hline
\end{tabular}

expression of PR, ER, and HER2 ( $P=0.004,0.599$, and 0.001, respectively) (Fig. 2). Table 3 shows descriptives for the conditional probability of developing diabetes over time in patients with $\mathrm{BC}$ treated with comprehensive therapy after adjustment for age and BMI. The risk of developing secondary diabetes for subjects with advanced BC (hazard ratio $(\mathrm{HR})=1.623 ; 95 \%$ confidence interval $(\mathrm{CI}) 1.128-$ $2.335(P<0.01))$ was higher than for those with early $\mathrm{BC}$. Although the risk of developing secondary diabetes for patients with negative $\mathrm{PR}$ expression $(\mathrm{HR}=0.530 ; 95 \%$ CI 0.372-0.755 $(P<0.001))$ was higher than for those with positive PR expression, the risk of developing secondary diabetes for patients with negative ER expression was slightly higher than for those with positive ER expression
$(\mathrm{HR}=0.806 ; 95 \%$ CI $0.566-1.146(P=0.230))$, which was not statistically significant. Furthermore, the risk of developing secondary diabetes for the patients with positive HER2 expression $(\mathrm{HR}=1.822 ; 95 \%$ CI 1.230-2.700 $(P<0.01))$ was higher than for those with negative HER2 expression. The risk of developing secondary diabetes for subjects with lymph node metastasis $(\mathrm{HR}=1.595 ; 95 \% \mathrm{CI}$ 1.128-2.258 $(P<0.01))$ was higher than for those without lymph node metastasis. Menopausal status did not significantly modulate systemic therapy-diabetes risk association. Therefore, pathological stages, lymph node metastasis status, hormone receptor expression, and HER2 expression were independent risk factors for developing secondary diabetes for the $\mathrm{BC}$ patients after systemic therapy. 

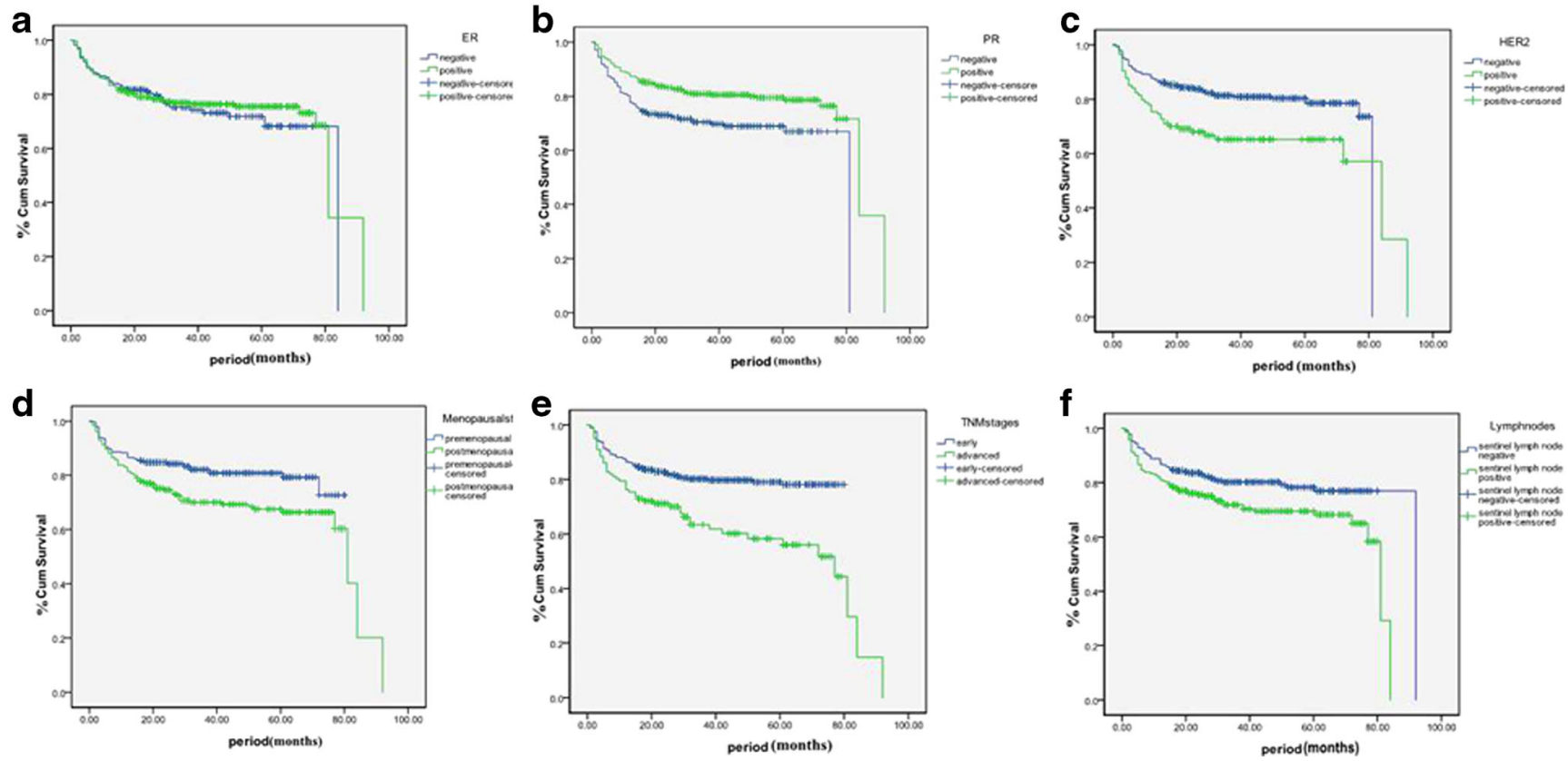

Fig. 2 The risk rate for secondary diabetes and IFG in breast cancer patients with ER-positive group and ER-negative group. a The risk rate for secondary diabetes and IFG in breast cancer patients with PR-positive group and PR-negative group. $\mathbf{b}$ The risk rate for secondary diabetes and IFG in breast cancer patients with HER2 positive group and HER2 negative group. $\mathbf{c}$ The risk rate for secondary diabetes and IFG in breast

cancer patients with premenopausal group and postmenopausal group. $\mathbf{d}$ The risk rate for secondary diabetes and IFG in breast cancer patients with sentinel lymph node metastasis group and without sentinel lymph node metastasis group. e The risk rate for secondary diabetes and IFG in breast cancer patients with early stage group and advanced stage group

\section{Follow-up and clinical outcome}

Complete follow-up information was collected from all the patients in this study. The median follow-up was 41 months (16-66). Of the 59 patients with preexisting diabetes, $94.7 \%$
(54/59) received anti-diabetes therapy and $8.5 \%(5 / 59)$ recovered to normal FPG levels after using diet and exercise. Two patients discontinued chemotherapy due to severe diabetesrelated adverse effects. Overall, 189 patients died during the observation period; $7.95 \%(12 / 151)$ of those with preexisting
Table 3 Median onset time and $95 \%$ confidence intervals for secondary diabetes and IFG after systemic therapy for breast cancer patients

\begin{tabular}{|c|c|c|c|}
\hline & Median onset time (months, $95 \% \mathrm{CI}$ ) & $P$ values & $\begin{array}{l}P \text { values (adjusted } \\
\text { for age and } \mathrm{BMI} \text { ) }\end{array}$ \\
\hline \multicolumn{4}{|l|}{ TNM stages } \\
\hline $\begin{array}{l}\text { Early } \\
\text { Advanced }\end{array}$ & $\begin{array}{l}65.667(62.867,68.468) \\
54.880(47.667,62.093)\end{array}$ & 0.000 & 0.009 \\
\hline \multicolumn{4}{|l|}{ Menopausal status } \\
\hline $\begin{array}{l}\text { Premenopausal } \\
\text { Postmenopausal }\end{array}$ & $\begin{array}{l}66.111(62.678,69.543) \\
61.736(56.208,67.265)\end{array}$ & 0.003 & 0.111 \\
\hline \multicolumn{4}{|l|}{ ER } \\
\hline $\begin{array}{l}\text { Negative } \\
\text { Positive }\end{array}$ & $\begin{array}{l}64.153(59.576,68.730) \\
67.551(61.036,74.066)\end{array}$ & 0.599 & 0.230 \\
\hline \multicolumn{4}{|l|}{ PR } \\
\hline $\begin{array}{l}\text { Negative } \\
\text { Positive }\end{array}$ & $\begin{array}{l}58.921(54.263,63.578) \\
71.312(65.877,76.746)\end{array}$ & 0.004 & 0.000 \\
\hline \multicolumn{4}{|l|}{ HER2 } \\
\hline $\begin{array}{l}\text { Negative } \\
\text { Positive }\end{array}$ & $\begin{array}{l}67.085(64.212,69.958) \\
59.677(51.666,67.688)\end{array}$ & 0.001 & 0.003 \\
\hline \multicolumn{4}{|l|}{ Lymph nodes } \\
\hline $\begin{array}{l}\text { Negative } \\
\text { Positive }\end{array}$ & $\begin{array}{l}74.828(70.826,78.830) \\
60.264(75.368,86.632)\end{array}$ & 0.009 & 0.008 \\
\hline
\end{tabular}


diabetes, $13.56 \%(8 / 59)$ of those with secondary diabetes, $14.1 \%(162 / 1152)$ of those with normal FPG, and $9.72 \%$ $(7 / 72)$ of those with secondary IFG $(P=0.070)$. The recurrence percentage of $\mathrm{BC}$ patients is significantly higher in the secondary diabetes group $(P<0.05$, Table 2$)$. Three patients with secondary diabetes developed bilateral primary breast cancer, compared with two patients in the preexisting diabetes group. One secondary diabetes patient developed squamous cell lung cancer, and one preexisting diabetes patient developed ovarian cancer.

\section{Discussion}

BC and type 2 diabetes share similar etiologies, including hyperinsulinemia, hyperglycemia, and chronic inflammation [18]. Previous studies showed that both insulin resistance and diabetes positively affect cancer incidence [19-22]. However, the effect of BC and the use of systemic therapies for BC on the development of diabetes remains unclear [13]. In this study, we retrospectively investigated the potential association between systemic therapy and the incidence of type 2 diabetes in Chinese females with BC. A total of 1434 BC patients were followed up for a mean period of 41 months. Data revealed that the risk of developing diabetes after systemic therapy for the $\mathrm{BC}$ patients was higher than that for the normal control group $(1.4 \%)$, suggesting the potential association between systemic therapy and secondary diabetes in Chinese patients with BC. This increased incidence of secondary diabetes was associated with advanced $\mathrm{BC}$ stage at initial diagnosis.

A recent investigation revealed that the prevalences of diabetes and prediabetes in Chinese adults, 20 years of age or older, were $9.7 \%$ (10.6\% among men and $8.8 \%$ among women) and $15.5 \%$ (16.1 \% among men and $14.9 \%$ among women), respectively [23]. A study in Canada reported that $16.5 \%$ (1011/6107) of women with breast cancer aged 55-79 were diagnosed with diabetes at diagnosis, which is higher than the prevalence of $10.5 \%(151 / 1434)$ in our study [7]. This suggests that the level of economic development and different lifestyles and diets may affect the prevalence of diabetes in different populations. However, patients' age and the tendency for obesity were both considered to be risk factors for diabetes [7].

Recently, Ji et al. investigated the incidence of diabetes and prediabetes in 119 Chinese female adult BC patients after systemic treatment and found prevalences of 21.8 and $43.7 \%$, respectively [24]. Although these observations support our finding that patients with $\mathrm{BC}$ after systemic therapy tended to develop secondary diabetes, the increased incidence of diabetes was higher than in the current study. There are several possible reasons for this discrepancy. Firstly, they measured $2 \mathrm{~h}$ plasma glucose levels through OGTT, which were increased in $80.0 \%$ of patients with normal FPG levels.
Secondly, they investigated only 119 BC patients, which was not a large cohort of breast cancer survivors. Finally, the mean follow-up duration was only 18 months in the study.

Similar to previous studies [25], our results indicated that breast cancer patients with preexisting diabetes tended to have a high percentage of older, menopausal, and obese patients. In addition, breast cancer patients with diabetes were more likely to have larger tumor size, later pathological stages, a higher rate of lymph node metastasis, and a higher rate of ERnegative expression, which was also consistent with the findings of Hou et al. [25]. In our study, later pathological stages and more lymph node metastasis in the diabetic breast cancer group indicate that hyperinsulinemia promotes tumor cell proliferation and metastasis to some extent, which may be associated with interaction between insulin and its receptor, which may active the PI3K and Ras-MAPK pathways. Therefore, this study supports the hypothesis that diabetes is a high-risk factor affecting the growth of breast tumors and axillary lymph node metastasis. Therefore, systemic treatments for the breast cancer patients with diabetes have to be tailored to the individual, and strict control of blood sugar level is absolutely important.

Furthermore, our study suggests that secondary diabetes was associated with later pathological stages, more lymph node metastasis, and higher incidence of distance recurrence. The risk of developing abnormal plasma glucose levels after systemic therapy was significantly higher in patients with advanced stages than in patients with early stages. Patients with secondary diabetes were associated with a significantly higher risk of distance metastasis than patients with preexisting diabetes. One possible explanation for this is that hyperglycemia, hyperinsulinemia, and inflammation occur in newly diagnosed diabetes, which can result in tumor cell proliferation and metastasis [26-30]. However, hyperglycemia and hyperinsulinemia may exist rarely in patients with preexisting diabetes because blood glucose levels are usually controlled well using oral hypoglycemic agents or insulin. Nevertheless, because we did not have detailed information regarding insulin and glucose levels or the dose of oral hypoglycemic agents or insulin, further experiments are needed to be carried out to understand the underlying mechanism.

Very limited literature is currently available regarding the risk of secondary diabetes among breast cancer survivors. A study [12] provides evidence for an increased incidence of diabetes among postmenopausal breast cancer survivors, at age 55 or older, especially for patients who received adjuvant chemotherapy. Our results indicated that breast cancer patients with later pathological stages, more lymph node metastasis, negative hormone receptor expression, and positive HER2 expression tended to have a higher percentage of risk to develop secondary diabetes and IFG. Actually, the BC patients with the above clinical pathological characteristics, which are associated with poor prognosis, may receive more cycles of 
standard chemotherapy in the current study, which may contribute to the increased incidence of developing secondary type 2 diabetes. This study supports the hypothesis that BC patients after adjuvant chemotherapy experienced a higher rate of diabetes, at least in part, which is consistent with results of the previous study [12]. This conclusion is supported by a number of recent observations. First, Feng et al. reported that 5-FU-based chemotherapy might affect beta cell function by causing acute beta cell damage at the early phase and chronic damage at the later phase [31]. Second, other types of chemotherapy agents such as vinblastine and taxanes, which target microtubules and microfilaments, may inhibit the release of insulin and then increase blood sugar levels [32]. In addition, glucocorticoids are used commonly to reduce allergic or gastrointestinal adverse reactions during chemotherapy, which may cause temporary hyperglycemia [33-37]. Furthermore, the weight gain caused by high-energy diet and estrogen suppression during chemotherapy may further promote diabetes [38-40]. Finally, the impaired hepatic and renal functions caused by chemotherapy were suggested to be risk factors for the development of diabetes [41]. Nevertheless, the lack of a control group of $\mathrm{BC}$ patients without chemotherapy in our study means that the precise mechanism for our findings is unclear, and so further studies using an additional control cohort are needed to explore this relationship.

Nonetheless, our study has some limitations. It is important to note that the current study may be affected by the limited sample size (1434 cases) from three centers in one area. An additional national multicenter trial is needed to achieve a definitive conclusion regarding the effect of adjuvant therapy for $\mathrm{BC}$ patients on the incidence of secondary diabetes. It was reported that secondary diabetes was associated with significantly increased mortality [4]; however, we did not observe this association. This may be due to the different follow-up times, as the relative risk of diabetes for BC patients may increase over time [14]. In addition, we also did not have information regarding the use of prescription drugs, the doses of chemotherapy agents (such as vinblastine, taxanes, or glucocorticoids), or the dose of endocrine therapies such as tamoxifen, which was associated with an increased risk of diabetes among older females [42-45].

In summary, this large population-based study shows an increase in the incidence of diabetes among breast cancer survivors after systemic therapy, especially the patients with later pathological stages, more lymph node metastasis, negative hormone receptor expression, and positive HER2 expression. It is possible that chemotherapy is a factor leading to the increased risk of diabetes among the patients receiving systemic treatment. The reasons for this relationship are uncertain, and further research is necessary. In the meantime, greater diabetes screening and prevention strategies among breast cancer patients after systemic treatment are needed in China.
Acknowledgments This work was supported by the National Natural Science Foundation of China (Grant No. 81302314, 81201196, and 81471781).

\section{Conflicts of interest None}

Open Access This article is distributed under the terms of the Creative Commons Attribution 4.0 International License (http:// creativecommons.org/licenses/by/4.0/), which permits unrestricted use, distribution, and reproduction in any medium, provided you give appropriate credit to the original author(s) and the source, provide a link to the Creative Commons license, and indicate if changes were made.

\section{References}

1. $\mathrm{Xu} \mathrm{Y}$, Wang $\mathrm{L}, \mathrm{He} \mathrm{J}$, et al. Prevalence and control of diabetes in Chinese adults. JAMA. 2013;310(9):948-59.

2. Ferlay J, Soerjomataram I, Ervik M, Forman D, Bray F, et al. Globocan 2012: estimated cancer incidence, mortality and prevalence worldwide in 2012. [DB/OL]: http://globocan.iarc.fr/Pages/ fact sheets population.aspx, 2014-01-09/2014-03-03.

3. Zheng S, Bai JQ, Li J, et al. The pathologic characteristics of breast cancer in China and its shift during 1999-2008: a national-wide multicenter cross-sectional image over 10 years. Int J Cancer. 2012;131(11):2622-31.

4. Larsson SC, Mantzoros CS, Wolk A. Diabetes mellitus and risk of breast cancer: a meta-analysis. Int J Cancer. 2007;121:856-62.

5. Lipscombe LL, Goodwin PJ, Zinman B, McLaughlin JR, Hux JE. Diabetes mellitus and breast cancer: a retrospective populationbased cohort study. Breast Canc Res Treat. 2006;98:349-56.

6. Liao S, Li J, Wang L, Zhang Y, et al. Type 2 diabetes mellitus and characteristics of breast cancer in China. Asian Pac J Cancer Prev. 2010;11(4):933-7.

7. Lipscombe LL, Goodwin PJ, Zinman B, McLaughlin JR, Hux JE. The impact of diabetes on survival following breast cancer. Breast Canc Res Treat. 2008;109:389-95.

8. Peairs KS, Barone BB, Snyder CF, et al. Diabetes mellitus and breast cancer outcomes: a systematic review and meta-analysis. J Clin Oncol. 2011;29:40-6.

9. Simon D, Balkau B. Diabetes mellitus, hyperglycaemia and cancer. Diabetes Metab. 2010;36:182-91.

10. Villarini A, Pasanisi P, Raimondi M, Gargano G, Bruno E, Morelli $\mathrm{D}$, et al. Preventing weight gain during adjuvant chemotherapy for breast cancer: a dietary intervention study. Breast Cancer Res Treat. 2012;135(2):581-9.

11. Suissa S, Azoulay L, Dell'Aniello S, Evans M, Vora J, Pollak M. Long-term effects of insulin glargine on the risk of breast cancer. Diabetologia. 2011;54:2254-62.

12. Lipscombe LL, Chan WW, Yun L, Austin PC, Anderson GM, Rochon PA. Incidence of diabetes among postmenopausal breast cancer survivors. Diabetologia. 2013;56:476-83.

13. Griffiths RI, Danese MD, Gleeson ML, et al. Epidemiology and outcomes of previously undiagnosed diabetes in older women with breast cancer: an observational cohort study based on SEERMedicare. BMC Cancer. 2012;12:613.

14. Alberti KG, Zimmet PZ. Definition, diagnosis and classification of diabetes mellitus and its complications. Part 1: diagnosis and classification of diabetes mellitus provisional report of a WHO consultation. Diabet Med. 1998;15:539-53.

15. Choo V. WHO reassesses appropriate body-mass index for Asian populations. Lancet. 2002;360:235. 
16. National Cancer Institute. Common Terminology Criteria for Adverse Events (CTCAE) v.4.0 2010. http://ctep.cancer.gov/ protocolDevelopment/electronic applications/ctc.htm\#ctc 40

17. Yi Huang, Xiaoyan Cai, Miaozhen Qiu, et al. Prediabetes and the risk of cancer: a meta-analysis. Diabetologia. 2014; 2014 Sep 11.

18. Noto H, Tsujimoto T, Sasazuki T, Noda M. Significantly increased risk of cancer in patients with diabetes mellitus: a systematic review and meta-analysis. Endocr Pract. 2011;17:616-28.

19. Hardefeldt PJ, Edirimanne S, Eslick GD. Diabetes increases the risk of breast cancer: a meta-analysis. Endocr Relat Cancer. 2012;19(6): 793-803.

20. Jiralerspong S, Kim ES, Dong W, et al. Obesity, diabetes, and survival outcomes in a large cohort of early-stage breast cancer patients. Ann Oncol. 2013;24(10):2506-14.

21. Lipscombe LL, Goodwin PJ, Zinman B, McLaughlin JR, Hux JE. Increased prevalence of prior breast cancer in women with newly diagnosed diabetes. Breast Canc Res Treat. 2006;98:303-9.

22. Rui-jue W, Lin-jie L, Liang-bin J, et al. Clinicopathologic features of breast cancer patients with type 2 diabetes mellitus in southwest of China. Med Oncol. 2014;31:788.

23. Yang W, Juming L, Weng J, et al. Prevalence of diabetes among men and women in China. N Engl J Med. 2010;362:1090-101.

24. Guang-yan J, Liang-bin J, Rui-jue W, et al. Incidences of diabetes and prediabetes among female adult breast cancer patients after systemic treatment. Med Oncol. 2013;30:687.

25. Hou G, Zhang S, Zhang X, et al. Clinical pathological characteristics and prognostic analysis of 1,013 breast cancer patients with diabetes. Breast Cancer Res Treat. 2013;137:807-16.

26. Fujioka K. Pathophysiology of type 2 diabetes and the role of incretin hormones and beta-cell dysfunction. JAAPA. 2007;Suppl: 3-8.

27. Liao S, Li J, Wei W, et al. Association between diabetes mellitus and breast cancer risk: a meta-analysis of the literature. Asian Pac J Cancer Prev. 2011;12:1061-5.

28. Fleming ST, Pursley HG, Newman B, et al. Comorbidity as a predictor of stage of illness for patients with breast cancer. Med Care. 2005;43:132-40

29. Srokowski TP, Fang S, Hortobagyi GN, et al. Impact of diabetes mellitus on complications and outcomes of adjuvant chemotherapy in older patients with breast cancer. J Clin Oncol. 2009;27:2170-6.

30. Van de Poll-Franse LV, Houterman S, Janssen-Heijnen ML, et al. Less aggressive treatment and worse overall survival in cancer patients with diabetes: a large population based analysis. Int J Cancer. 2007;120:1986-92.

31. Feng J-P, Yuan X-L, Li M, Fang J, Xie T, Zhou Y. Secondary diabetes associated with 5-fluorouracil-based chemotherapy regimens in non-diabetic patients with colorectal cancer: results from a single centre cohort study. Colorectal Dis. 2013;15(1):2733.

32. Singh SP, Gao Y, Singh LD, Kunapuli SP, Ravindra R. Role of microtubules in glucose uptake by C6 glioma cells. Pharmacol Toxicol. 1998;83(2):83-9.

33. Biddinger SB, Kahn CR. From mice to men: insights into the insulin resistance syndromes. Annu Rev Physiol. 2006;68:123-58.

34. Almon RR, Dubois DC, Jin JY, et al. Temporal profiling of the transcriptional basis for the development of corticosteroid-induced insulin resistance in rat muscle. J Endocrinol. 2005;184:219-32.

35. Buren J, Lai YC, Lundgren M, et al. Insulin action and signalling in fat and muscle from dexamethasone-treated rats. Arch BiochemBiophys. 2008;474:91-101.

36. King EM, Holden NS, Gong W, et al. Inhibition of NF-kappaBdependent transcription by MKP-1: transcriptional repression by glucocorticoids occurring via p38 MAPK. J Biol Chem. 2009;284:26803-15.

37. Mazziotti G, Gazzaruso C, Giustina A. Diabetes in Cushing syndrome: basic and clinical aspects. Trends Endocrinol Metab. 2011;22:499-506

38. Renehan AG, Tyson M, Egger M, et al. Body-mass index and incidence of cancer: a systematic review and meta-analysis of prospective observational studies. Lancet. 2008;371:569-78.

39. Goodwin PJ, Ennis M, Pritchard KI, et al. Adjuvant treatment and onset of menopause predict weight gain after $\mathrm{BC}$ diagnosis. J Clin Oncol. 1999;17:120-9.

40. Goodwin PJ, Ennis M, Pritchard KI, et al. Fasting insulin and outcome in early-stage breast cancer: results of a prospective cohort study. J Clin Oncol. 2002;20:42-51.

41. Du W, Simon MS. Racial disparities in treatment and survival of women with stage I-III breast cancer at a large academic medical center in metropolitan Detroit. Breast Cancer Res Treat. 2005;91:243-8.

42. Decensi A, Robertson C, Viale G, et al. A randomized trial of lowdose tamoxifen on breast cancer proliferation and blood estrogenic biomarkers. J Natl Cancer Inst. 2003;95:779-90.

43. Guerrieri-Gonzaga A, Robertson C, Bonanni B, et al. Preliminary results on safety and activity of a randomized, double-blind, $2 \times 2$ trial of low-dose tamoxifen and fenretinide for breast cancer prevention in premenopausal women. J Clin Oncol. 2006;24:129-35.

44. Guvakova MA, Surmacz E. Tamoxifen interferes with the insulinlike growth factor I receptor (IGF-IR) signaling pathway in cells. Cancer Res. 1997:57:2606-10.

45. Bouzakri K, Karlsson HK, Vestergaard H, et al. IRS-1 serine phosphorylation and insulin resistance in skeletal muscle from pancreas transplant recipients. Diabetes. 2006;55:785-91. 